$15 .{ }^{4} \mathrm{~A}$ further study reported success in 51 of 55 patients considered by the surgeon to have acute inflammation, although only nine patients had severe disease. ${ }^{5}$ In our series, conversion to open surgery was required in two patients out of $31(6 \%)$ comparing favourably with the conversion rates in series of elective surgery. ${ }^{11}$ We have shown that laparoscopic surgery may be performed safely in severe complicated cholecystitis with minimal morbidity when surgeons have sufficient experience. Patients recover rapidly from the procedure, usually with dramatic resolution of symptoms, and seem to enjoy the same benefits as those undergoing elective surgery.

In our experience, about $10 \%$ of patients with symptomatic gall stones required emergency surgery for acute cholecystitis which fails to settle on conservative management. As many as a quarter of patients with symptomatic gall stone disease present acutely, and this trend may be increasing. ${ }^{12}$ Acute cholecystitis constitutes an important and increasing proportion of the surgical workload. We think that these patients should not be denied the benefits of laparoscopic cholecystectomy in centres with appropriate experience.

1 Cuschieri A, Dubois F, Mouiel J, et al. The European experience with laparoscopic cholecystectomy. Am J Surg 1991;161:385-7.

2 Dubois F, Icard P, Berthelot G, Levard H. Coelioscopic cholecystectomy. Ann Surg 1990;211:60-3.

3 Cooperman AM. Laparoscopic cholecystectomy for severe acute embedded and gangrenous cholecystitis. $\mathcal{F}$ Lap Surg 1990;1:37-40.

4 Flowers JL, Bailey RW, Scovill WA, Zucker KA. The Baltimore experience with laparoscopic management of acute cholecystitis. Am J Surg 1991;161: 388-92.

5 Unger SW, Edelman DS, Scott JS, Unger HM. Laparoscopic treatment of acute cholecystitis. Surgical Laparoscopy and Endoscopy 1991;1:14-6.

6 Reddick EJ, Olsen DO. Laparoscopic laser cholecystectomy. Surg Endosc 1989:3:1333.

7 Holohan TV. Laparoscopic cholecystectomy. Lancet 1991;338:801-3.

8 Wilson P, Leese T, Morgan WP, Kelly JF, Brigg JK. Elective laparoscopic cholecystectomy for "all-comers". Lancet 1991;338:795-7.

9 McArthur P, Cuschieri A, Sells RA, Sheilds R. Controlled clinical trial comparing early with interval cholecystectomy for acute cholecystitis. $\mathrm{Br} \mathcal{J}$ comparing early with int

10 Zucker KA, Bailey RW, Gadacz TR, Imbembo AL. Laparoscopic guided cholecystectomy. Am f Sur 1991;161:36-44.

11 Meyers WC, Branum GD, Farouk M, et al. A prospective analysis of 1518 laparoscopic cholecystectomies. $N$ Engl f Med 1991;324:1073-8.

12 Reiss R, Nudelman I, Gutman C, Deutsch A. Changing trends in surgery for acute cholecystitis. World f Surg 1990;14:567-71.

(Accepted l6 fune 1992)

\section{Asthma and open cast mining}

\section{J M F Temple, A M Sykes}

Glynneath, West

Glamorgan SA11 5AL

J M F Temple, general

practitioner

University College,

Swansea

A M Sykes, lecturer in

statistics

Correspondence to: $\mathrm{Dr}$

Temple, 102 High Street.

BMf 1992;305:396-7
Following Welsh Office concern about apparently excessive prescribing for asthma in 1983, the Glynneath practice started to audit its treatment of new asthma episodes. The method chosen was to check the treatment of a sample of such episodes. For this the practice requires a complete record of the asthmatic attacks it treats. As a consequence of this audit the practice became concerned that local industry was aggravating its patients' asthma. These fears were voiced at a public inquiry into proposals to open cast mine an area to the north of the town. When the secretary of state granted permission to start the mine a natural experiment began to test the hypothesis that the weekly number of new episodes of asthma treated by the town's general practitioners would increase when the new mine started.

\section{Methods and results}

The Glynneath practice has recorded new episodes of asthma (using a standard definition) on a computer database since late 1989. As a result the practice is well placed to note changes in the weekly number of new episodes of asthma presenting.

The graphical cusum technique is widely used in

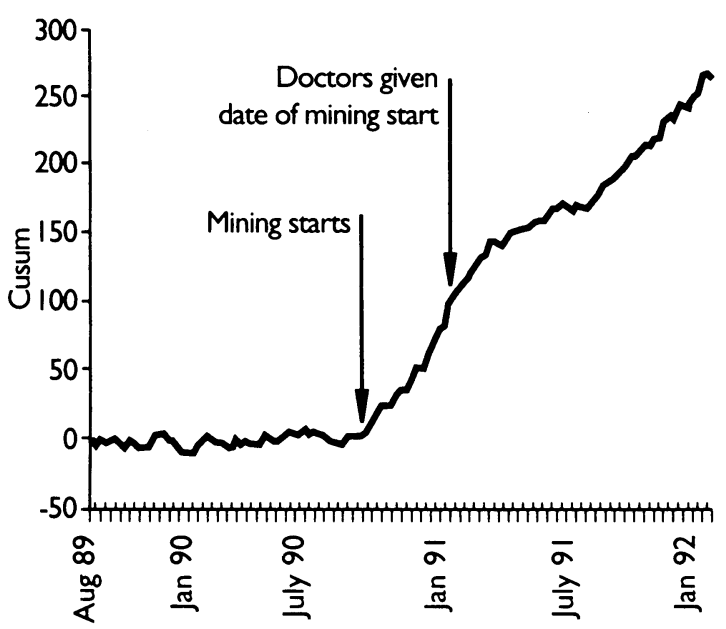

quality control and has recently been described by Williams $e t$ al in this respect. ${ }^{\prime}$ It is also suited to surveillance studies as any change in frequency of an illness presenting (compared with the reference level) is shown as a sustained change in gradient. A sudden change is indicated by a discontinuity in the graph at the time of the change. Thus the time of a change can be identified and possible causes investigated. In this case the mean weekly number of new episodes of asthma for the initial 25 weeks of the computerised database was used as the reference value. The cusum method was chosen because $(a)$ the start of the new mining operations was withheld from the investigators so as to avoid bias; $(b)$ if any indicated time of change coincided with the start of mining, then this would lend support to the hypothesis; $(c)$ it is an elegant method that is arithmetically simple, visually attractive, and intuitively understandable.

To confirm that any change noted was unlikely to be due to chance the $95 \%$ confidence intervals of the mean weekly new episodes of asthma before and after mining were calculated and significance of the difference tested.

Weekly new episodes of asthma were recorded by using a standard Wednesday to Tuesday week for the period 30 September 1989 to 14 January 1992. The gradient of the cusum graph showed a sustained and sudden change from the week beginning 3 October 1990 (fig). The new mine started excavation on 29 September 1990. Thus the average number of new episodes of asthma rose at about the time the mine started. The doctors learnt of the date mining started on 31 January 1991. There were no changes in practice personnel during the period of the investigation.

Before mining operations the mean weekly number of new episodes of asthma was 4.4 (95\% confidence interval 3.6 to 5.2 ), and after mining began it was 7.9 $(7 \cdot 0$ to $8 \cdot 6)$. The $95 \%$ confidence interval for the change in mean was $2 \cdot 3$ to 4.6 weekly new episodes of asthma. A test of the hypothesis of equality of the means was rejected with a $z$ statistic of $6.04(p<0.001)$

\section{Comment}

There is widespread concern that environmental degradation is causing ill health. European law requires that any major industrial development is assessed for its likely effect on human health. ${ }^{2}$ There are few studies of the effect of industries on the general community. ${ }^{34}$ However, Kirn reported concern that one cause of the
Cumulative sum (cusum) of weekly new episodes of asthma 
current increase in asthma deaths may be increasing atmospheric pollution. ${ }^{5}$

In this study, collecting the data blind and the absence of obvious change in gradient occurring when the doctors learnt of the date mining started excluded bias as the cause of the changes recorded. The sustained change in gradient after the start of mining suggests that the cause of the change had also continued. Thus it could not be due to seasonal or other transient factors.

Our findings are prima facie evidence to support the practice's concern about the risks to the general population from the open cast coal site. The results of this small study give cause for national concern in view of the current increasing trend towards open cast mining in Britian.

1 Williams SM, Parry BR, Schlup MMT. Quality control: an application of the cusum. BMJ 1992;304:1359-61.

2 European Council. Directive of 27 June 1985 on the assessment of the effects of certain public and private projects on the environment. Official fournal of the European Communities 1985;175:40-85. (85/337/EEC.)

3 Newhouse ML, Thompson H. Mesothelioma of pleura and peritoneum following exposure to asbestos in the London area. Br $\mathcal{J}$ Industr Med following expos

4 Lloyd OL. Respiratory cancer clustering associated with localised industrial air pollution. Lancet 1978;i:318-20.

$5 \mathrm{Kirn}$ TF. Asthma mortality rate raises questions, emphasizes need to determine facts of situation. $\mathcal{F A M A} 1988 ; 260: 455-6$.

(Accepted II fune 1992)

\title{
BASDEC: a novel screening instrument for depression in elderly medical inpatients
}

\author{
Fiona Adshead, Diana Day Cody, Brice Pitt
}

\section{Royal Postgraduate Medical School, Hammersmith Hospital, London W12 \\ Fiona Adshead, senior house officer, department of medicine for the elderly Diana Day Cody, senior registrar, department of psychological medicine Brice Pitt, professor of psychiatry of old age}

Correspondence to (and free copies of BASDEC through): Professor Pitt.

BMJ 1992;305:397
Depression is a common cause and consequence of ill health in old people. ${ }^{1}$ It hinders rehabilitation and hastens death, yet the diagnosis is often missed in medical wards. ${ }^{2}$

Screening questionnaires such as the geriatric depression scale $(\mathrm{GDS})^{3}$ help with recognising depression, which can then be assessed for treatment. The brief assessment schedule (BAS) ${ }^{4}$ was used successfully by lay interviewers to screen for depression among residents of old people's homes. ${ }^{5}$ In a typical hospital ward, however, the questions are too easily overheard.

We compare the GDS with a novel adaptation of the depression scale of the BAS as a deck of cards (BASDEC, BAS depression cards) in screening geriatric inpatients for depression.

\section{Method and results}

BASDEC comprises 19 cards, $8.2 \mathrm{~cm} \times 10.4 \mathrm{~cm}$, with statements derived from the depression scale of the BAS in large black print on a white background. They are presented one at a time, to be answered "True" or "False" according to the subject's present feelings. Every response of true gains one point, except "I've given up hope" and "I've seriously considered suicide," which each score two. "Don't know" responses, which are discouraged, score half a point. The maximum score is 21 .

The study was carried out in the wards of the department of medicine for the elderly in the Hammersmith Hospital. Willing, cognitively intact patients who could understand English and read large print were given BASDEC and the GDS. The interviewer read the 30 questions of the GDS to those who could not read them.

A total of 79 subjects were offered BASDEC and one refused; 79 were offered the GDS and seven refused. Of the 72 subjects completing both tests, 21 were men, 51 women, with a mean age of 78.9. BASDEC took a mean 3.4 minutes to complete (range $2 \cdot 0-8 \cdot 0$ ), the GDS a mean $6 \cdot 8$ minutes (range $4 \cdot 0-12 \cdot 0$ ).

Cut off scores for possible "caseness" were 7 for BASDEC $^{45}$ and 14 (out of 30) for the GDS. ${ }^{3} \mathrm{~A}$ psychiatrist (DDC) who was blind to the scores obtained on the screening instruments confirmed caseness: (either primary or secondary affective disorder or dysthymic disorder) or not. This interview almost always took place within three days of the screening procedure and in the same half of the day.
Twenty three subjects scored 7 or more on BASDEC and 23 scored 14 or more on the GDS, and the psychiatrist diagnosed 24 cases (four primary affective disorder, 18 secondary affective disorder, two dysthymic disorder). The relations between caseness according to the respective screening instruments and the psychiatrist are shown in the table. Although there were conflicting results between the instruments in 10 patients (four cases and six non-cases), both instruments performed identically well, having a sensitivity of $71 \%$, a specificity of $88 \%$, a positive predictive value of $74 \%$, and a negative predictive value of $86 \%$.

"Caseness" and psychiatric diagnosis on brief assessment schedule depression cards (BASDEC) and geriatric depression scale (GDS)

\begin{tabular}{lllllll} 
& \multicolumn{2}{c}{$\begin{array}{c}\text { Psychiatric case } \\
\text { BASDEC }\end{array}$} & & \multicolumn{2}{c}{$\begin{array}{c}\text { Not a psychiatric case } \\
\text { BASDEC }\end{array}$} & \\
\cline { 2 - 3 } & $<7$ & $\geqslant 7$ & & $<7$ & $\geqslant 7$ & Total \\
\hline GDS $<14$ & 5 & 2 & & 39 & 3 & 49 \\
GDS $\geqslant 14$ & 2 & 15 & & 3 & 3 & 23 \\
\hline Total & 7 & 17 & & 42 & 6 & 72 \\
\hline
\end{tabular}

\section{Comment}

The psychiatrist's diagnosis of 24 of the 72 subjects $(33 \%)$ as suffering from some form of depressive disorder (in most cases secondary to their physical illness) used an extra dimension-the duration of symptoms. Though the screening instruments reflect the mood of the day to some extent, both performed well.

BASDEC proved an effective, user friendly way of screening medically ill elderly patients for depression in a ward setting. The GDS took twice as long to administer, and more patients refused it.

Novel, highly acceptable, and sufficiently valid, BASDEC deserves to be tried wherever a high prevalence of depression among the elderly is expected. It may also prove useful in general practice.

We thank Professor Christopher Bulpitt, Dr Claire Nicholl, and Dr Astrid Fletcher for support and encouragement; Dr Mario Impallomeni for permission to interview his patients; Dr Jane Wadsworth for advice on the presentation of the statistics; and E Merck Pharmaceuticals for printing and providing the cards.

1 Cooper B. Psychiatric disorders among elderly patients admitted to general hospital wards. $7 R$ Soc Med 1987;80:13-6.

2 Goldberg D. Identifying psychiatric illness among general medical patients. BMF 1985;291:161-2.

3 Yesavage J, Brink T, Rose T, Lum $O$, Huang V, Adey M, Leirea $O$. Development and validation of a geriatric depression screening scale: preliminary report. $\mathcal{F}$ Psychiatric Res 1983;17:37-49.

4 Macdonald A, Mann A, Jenkins R, Richard L, Godlove C, Rodwell G. An attempt to determine the impact of four types of care upon the elderly in London by the study of matched groups. Psychol Med 1982;12:193-200.

5 Mann A, Graham N, Ashby D. Psychiatric illness in residential homes for the elderly: a survey in one London borough. Age Ageing 1984;13:257-65.

(Accepted 8 fune 1992) 